\title{
Methods for creating CLT Construction Guidelines
}

\author{
Simen Wahlstrøm ${ }^{1, *}$ \\ ${ }^{1}$ Norconsult AS Department of Building Physics, 1338 Sandvika, Norway
}

\begin{abstract}
During the past decade, the use of Cross-Laminated Timber (CLT) elements has become gradually more popular and widespread in building construction in Norway. A study mapping the experience of CLT use in the Norwegian construction industry reveals that existing domestic literature on this topic is outdated and no longer relevant. This paper describes the methods used for preparing updated CLT construction guidelines. Information obtained from expert actors in the construction industry, combined with document studies, has formed the knowledge basis for this study. A total of 19 qualitative in-depth interviews were conducted, and more than 400 documents from 12 CLT projects were received from 11 actors. A CLT construction guide focusing on moisture safety design and rational production was prepared based on the information obtained, and was quality assured by 16 experts from industry and the research community. Guidance on the approach to preparation of the guide, its format and layout, was provided by SINTEF Science Communication. Critical feedback influenced the content of the guide and its design recommendations. The study shows that dialogue with the construction industry and research community is a valuable contribution to the preparation of structured construction solutions. The involvement of the industry has accentuated the importance of the preparation of CLT construction guidelines. It is hoped that the guide will inspire research institutions to prepare and publish updated guidelines.
\end{abstract}

\section{Introduction}

In the last two decades, the development and use of Cross-Laminated Timber (CLT) elements have gradually become more widespread in the construction sector [1]. During the last ten years in particular, CLT-based construction systems have been applied more extensively, especially in Norway. The Norwegian government has stated that an increase in the domestic production and use of CLT is desirable [2]. Expansion in the use of CLT is also the result both of a desire to boost the domestic wood processing industry, and of the material's eco-friendly potential. Photosynthesis enables $\mathrm{CO}_{2}$ to be absorbed by growing trees where it is stored temporarily as carbon in building materials during their functional lifetimes [3]. Existing literature and research studies have demonstrated that the use of CLT has a lower carbon footprint than comparable building materials [3-5].

A study carried out to assess building physical challenges related to CLT construction has revealed knowledge gaps and shortcomings in relevant Norwegian literature [6]. The study conducted in-depth interviews with 19 experienced actors in the Norwegian construction sector in order to obtain their first-hand experience of, and their views on challenges related to, the CLT construction system [6]. The results showed that there is a need to update existing CLT guidelines, with a special focus on critical issues such as fire safety, acoustics and moisture behaviour. Due to the anticipated increase in the use of CLT elements in the future, it will be important to prepare new guidelines to support their sustainable and standardised use [6].

Due to more recent development trends in the industry, current Norwegian guiding literature on CLT construction [7-9] is outdated and essentially redundant in terms of practical application [6]. There are two research institutions in Norway that are responsible for publishing updated CLT guiding literature; SINTEF Community and the Norwegian Institute of Wood Technology (NIWT, Norsk Treteknisk Insitutt). SINTEF Community is the main source of research information and guiding literature in the Norwegian construction industry, published in the form of its Building Research Design Guides (construction guides) [10]. These guides offer design solutions in compliance with existing statutory regulations and are highly valued by the industry. The NIWT publishes general literature on the wood processing industry and the use of timber in construction applications, among others [11]. To date, both institutions have published only very few reports and guides that address CLT construction principles related to building physics. For this reason, there is a growing need to issue technical CLT guidelines in the same format as the existing Norwegian guides. The established format of such guidelines must be the subject of a comprehensive quality assurance process in order to monitor structured layouts, wording and drawing techniques. As well as practical instructions, typical

* Corresponding author: simen.wahlstrom@norconsult.com 
construction guides include illustrations and CAD drawings demonstrating recommended construction design details.

International CLT handbooks [3,9 and 12] also provide an important source of information that may be applied in the preparation of new guidelines for use in Norway, although it will be necessary to adapt these to Norwegian building traditions. As is stated in reference [6], Norwegian builders and construction companies have expressed a clear desire to ensure that CLT surfaces are visible in their constructions. However, the international handbooks [3,9 and 12] do not consider this to be an important issue. The Norwegian desire for visible CLT surfaces is thus at odds with recommendations expressed by the European CLT sector.

The main goal of this study is to demonstrate how high-quality CLT construction guidelines for use in Norway can be prepared. Due to a lack of extensive practical experience, key information has been obtained from industrial actors, supplemented with a literature review and quality assurance provided by the Norwegian research community. The study was carried out in the wake of that published by Wahlstrøm et al. [6], with the aim of closing the identified CLT knowledge gap. The guide discussed in this paper aims to adhere to existing SINTEF Community publishing guidelines, and to constitute a legal basis for contractor compliance with statutory regulations governing building projects in Norway. The paper focuses on descriptions of the methods used to create the guide, and is in part related to those described in Wahlstrøm et al. [6]. It also includes a comprehensive study of documents and a quality assurance process.

The study limits its scope to descriptions of CLT elements used in buildings, with a focus on building physical elements. Construction related to bridges and timber houses is not discussed. The structure of the guide uses a detached residential building with a maximum of three storeys as its reference model. However, the principles established here can also be applied to larger CLT building projects. The guide will serve to provide moisture safety design and a rational production process. Topics such as economics, statics, fire safety and acoustics are discussed only in general terms, and simply to illustrate our overall status of knowledge within the CLT sector. The paper is written as a part of a M.Sc Thesis entitled "Guidelines for CLT Construction", carried out at the Department of Civil and Environmental Engineering at the Norwegian University of Science and Technology (NTNU) in Trondheim, Norway, during the academic year 2018-2019 [13].

\section{Method}

This chapter describes the approach and methods used to prepare a CLT construction guide. The principal method is related to those described in Section 2.1 and in Wahlstrøm et al. [6].

This study combines a variety of methods including a literature review, interviews, a study of documents and a quality assurance process. The general approach has involved the use industry actors as a key source of information. Correspondence with, and input from, the industry have been important at all stages of the study. Figure 1 illustrates the various stages in the knowledge transfer method.

\subsection{Interviews conducted during previous studies}

Wahlstrøm et al. [6] provide a description of the interview process that was carried out in collaboration with SINTEF Community. The interviews adhered to the qualitative in-depth approach as described in Yin [14]. Qualitative interviews were preferred as a means of obtaining accounts of hands-on experience with the CLT system. A quantitative survey approach involving a mapping of incident frequency [15] was rejected. The interview informants comprised industry actors with experience from CLT construction projects. The interview approach enabled us to obtain an overall impression of the industry's challenges and research needs, and informants included representatives from project stakeholders, consultants (including architects), contractors and CLT suppliers. A comprehensive interview guide was prepared, which could be adjusted according to the category of actor. Although this study focuses mainly on building physical topics, and moisture behaviour in particular, questions regarding economics, statics, and environmental issues were also included in the interview guide.

A structured literature review was also carried out with the aim of mapping the existing literature on CLT construction. A total of 19 interviews were conducted either face-to-face or by telephone with actors in the

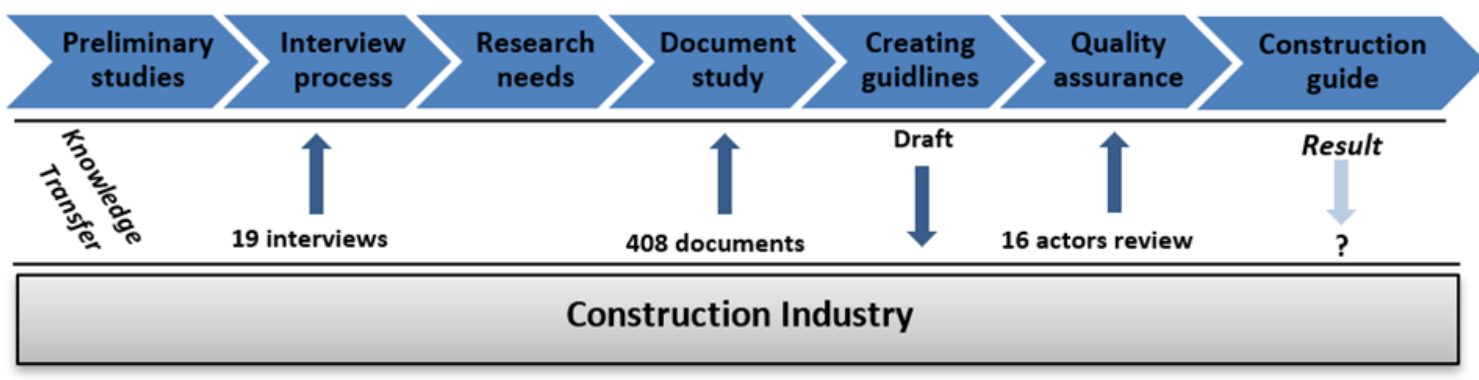

Fig. 1. Stages in the knowledge transfer method 
Norwegian construction industry. No written transcripts were taken, but a report was made from each interview. The reports were subsequently approved by the informants and archived in a common database so that they could be shared by all those involved in the project.

Information collected via these interviews is important as a source in the mapping of CLT research needs in Norway, as well as a basis for research funding applications. A mapping study of construction and design principles, production progress and procedures was also carried out, and this serves as the main source of information for much of the content of the construction guide.

During the interview process, networks were established between the author and a helpful and enthusiastic group of skilled construction industry actors. In our further research, we found it natural to continue our dialogue with these professionals. Such communication is important as part of our aim to close the knowledge gap pointed out by the industry informants.

\subsection{Document study}

The document study involved the collection, review and interpretation of relevant printed and electronic sources [16]. Analysis has involved a qualitative review and interpretation of document content with the aim of obtaining understanding and to accumulate empirical knowledge [16]. Such studies are useful for revealing the views of an entire group [17] - in this case, the construction industry. A structured document review is an iterative process that requires the careful re-reading of sorted data [16]. A document study of this type is commonly used as a source of information in qualitative research, often in combination with interviews [14]. In this study, the material in question comprises projectrelated documents containing CLT construction designs in the form of CAD illustrations and drawings. An analysis of such documents provides information on important issues related to CLT design, and in this study the information is applied as a source of construction details that can be used in the guide. It is important to bear in mind that the material derived from an analysis of this type has not been created with the aim of addressing a research objective [16]. It is usually written to serve organisational interests or for other specific purposes. It is thus important to exercise awareness and objectivity during the analysis process [14]. Since this study involves the interpretation and generalisation of its sources, it is important to bear in mind that specific construction details do not always serve as good generalisations.

The process of collecting documents was started during the interview process. Participating actors were asked to share project documents that contained construction details such as CLT designs. Additional documents were collected after research needs were identified and after the formulation of future research plans. The aim in collecting construction details was to use them as a foundation for developing recommendations for CLT construction design that could be included in the guide. Recommended design illustrations are an important aspect of the construction guides published by SINTEF Community. A structured procedure was created in order to obtain an overview, and as the basis for a plan for the review. The various sources were listed in order to facilitate the classification and sorting of documents and details by actor, project, construction element, content and assumed relevance. Chapter 3 describes the additional analytical processes and the results.

\subsection{Quality assurance}

One of the main objectives of this study was to create a guide that is useful to the industry. Close dialogue with both research institutions and the industry has been an important aspect of our methodical approach. Communication with the industry was key to the identification of research needs and for the acquisition of information and insights into topics that form a natural part of construction guides. Participating actors were permitted to quality assure the guide in order to ensure that their interests and input were preserved, and this process in turn provided further input. Participants were permitted to add additional information that they felt was overlooked or unavailable during the initial data gathering process. This procedure has also reduced the likelihood of false reporting [14]. Quality assurance was carried out both during the interview process and during preparation of the guide, and was backed up by the informants' approval of the author's interview reports [6].

Dialogue with representatives from SINTEF Community was crucial during preparation of the guide. A meeting was held early in this process between the author and the Department of Knowledge at SINTEF Community. A tutorial was held providing an introduction to standard guide writing procedures. This provided the author with insights into approaches and methods that would be beneficial during the study. The meeting involved reflecting on both content, layout and linguistic formalities. The author maintained regular contact with personnel at SINTEF Community in order to obtain guidance.

Once the guide was drafted, a comprehensive quality assurance process was set in motion. More than 25 people from industry and the research community were invited to participate, including 11 actors that had shared documents and some of the 19 interview informants. Actors with CLT competence, recommended by other participants, were also asked to participate. A selection of researchers at SINTEF Community were also invited to participate according to their respective specialisations in the fields of fire safety, acoustics and moisture design. A set of questions addressing building physical and technical aspects was sent to the participants for their consideration while reviewing the draft. Participants were reminded to direct specific focus on construction details. They were also asked to comment on whether or not the guide served to close the knowledge gap, and if it 
adequately met the need for literature as expressed by the industry. Feedback from these various actors was collated and the final draft revised accordingly.

Since the findings from a document study should not be interpreted as objective truth [14], quality assurance has provided an important tool in securing the validity of the findings. At the conclusion of the study, the revised guide was reviewed by the staff at SINTEF Community who gave the introductory tutorial.

\subsection{Triangulation}

A qualitative study should seek at least two sources of evidence to confirm its findings [16]. This approach is called triangulation and is an important principle in research work. It means that a study should use a combination of methods and sources of information to study the same phenomenon [16]. Triangulation of observations is an important means of establishing the validity of acquired information, and provides a measure of the degree of convergence or divergence of the phenomena under observation. In this study, the principle of triangulation has played an important role, and has involved the combination of three different processes; a literature review, interviews, and a document study. An additional quality assurance process has consolidated the validity of the findings.

Wahlstrøm et al. [6] described the triangulation of the interview process with a review of existing literature and the collection of information from the industry. The literature review was key to the identification of topics addressed, and not addressed, by existing literature. The interviews provided information from a different perspective, and was valuable in revealing discrepancies between published knowledge and the current industry consensus. In general, findings from these two sources tended to corroborate each other. The principle of triangulation can be extended by adding another source of information - a document study. This is used to generate recommendations for CLT design. Findings in documents can be compared with construction details described in existing literature and with the information provided by informants during interviews. Comparisons of shared documents with published literature can be used to identify divergent perspectives, and comparisons of both of these sources with interviews serves as an effective check on the validity of the interview material.

\section{Results}

\subsection{Results from the document study}

More than 400 documents relating to a total of 12 CLT construction projects were collected from 11 actors. The majority of these documents contained CAD-drawings and illustrations showing CLT building design. Factors such as confidentiality, copyright issues and formatting differences meant that the documents varied somewhat in terms of the level of construction and CLT element mounting detail presented. The documents received were sorted into three main categories: construction details, mounting details, and other documents. The category other documents typically included internal construction guidelines, fire safety penetration guidelines and project information documents. All the documents received were found to be useful during the interpretation and analysis process. Table 1 gives an overview of the categories of the documents collected. Further statistics from the document study are presented in the M.Sc thesis [13].

Table 1. Categories of collected documents

\begin{tabular}{|c|c|}
\hline Category & Number of documents \\
\hline Construction details & 293 \\
\hline Mounting details & 73 \\
\hline Other documents & 42 \\
\hline Total & $\mathbf{4 0 8}$ \\
\hline
\end{tabular}

The study encountered two types of document sharing policy. Some actors permitted access to all documents incorporated in a project, in addition to those related to construction and mounting details. Such documents are not counted in the 408 summarised in Table 1. The number of documents made available to the study was thus very large, and invoked a comprehensive selection process. Most actors had pre-selected documents containing relevant construction details prior to sharing. The level of detail collected from this group of actors was thus somewhat lower, but was just as relevant as that contained in documents received from the first group.

The extraction of information during the document study was carried out by means of a systematic sorting process designed to identify the most relevant documents. This was an iterative process that commenced when the documents were received, and continued during the collection of details related to construction. The relevance of information was determined on the basis of the nature of the building components illustrated, the level of detail in the description of the use of CLT, as well as qualitative judgements made by the author.

The result of the selection process was interesting in that a total of 30 construction details were selected as highly relevant. A further investigation of details related to CLT element mounting was carried out in order to understand how CLT elements are interconnected. The main reason for the low number of highlighted details in the guide is in part because the author wanted to demonstrate the use of CLT in all building components. However, many of the collected details were relevant to CLT construction only in part because they describe the use of CLT elements in combination with other materials, such as concrete, brick, steel and in connection with framework systems. It should also be 
noted that the projects included mainly involved educational (schools/kindergartens) or commercial buildings, and not detached residential houses.

A few of the documents reviewed in this study triggered inspection of other existing literature, in particular three handbooks containing construction details [3, 9 and 12]. These handbooks turned out to be equally as relevant as the collected documents, and a combination of these two information sources was used to prepare the illustrations published in the guide. Layout and the design of details was carried out under the supervision of staff at NTNU and SINTEF Community.

\subsection{Construction guide}

Information extracted from the interviews and document study formed the foundation for preparation of the CLT construction guide, which focuses on moisture-safe design and a rational building process. Instructions are sorted by subject. Recommended CLT design approaches for all building components are illustrated using construction details, and both are generated with the aim of achieving compliance with Norwegian statutory building regulations. Construction details showing the use of CLT elements in exterior walls, window insertions, slabs and roofs, have been drawn by the author using AUTOCAD 2019 software. The base reference for the generation of construction details is a (maximum) three-storey, detached, residential house. This has been chosen in order to avoid close inspection in relation to the requirements set out in existing acoustics and fire safety regulations. The guide consists of 16 pages including instructions and illustrations. As such it complies with the format adopted by previous construction guides published by SINTEF Community. In order to be relevant to the Norwegian construction industry, the guide is written in Norwegian and is tailored to adhere to Norwegian building traditions. One of the illustrations in the guide is shown in Figure 2 (below), and a full-size version is reproduced in the M.Sc thesis [13].

\subsection{Quality assurance}

After the conclusion of a three-week review period, a total of 16 of the invited 25 reviewers had read and responded to the draft. In retrospect, this period should ideally have been longer, but this was not possible due to the author's deadline.

In general, the reviews provided important input to the final draft in terms of supportive and constructive feedback. The scope and format of comments varied from short messages to detailed comments on specific sentences and sections. An impression of the content of these comments is given in the following.

Many actors stated that the most important topics related to CLT construction were included and explained. Many also highlighted the overall importance of preparing CLT construction guidelines. The guide serves as an effective demonstration and a starting point for further discussion of the subject. Many comments were supportive of the choices made in relation to design principles and solutions. There remains some deviation in some specific subject areas, but this is simply a reflection of variations in design extracted from the collected documents. Some actors shared supplementary information that was subsequently added to the guide.

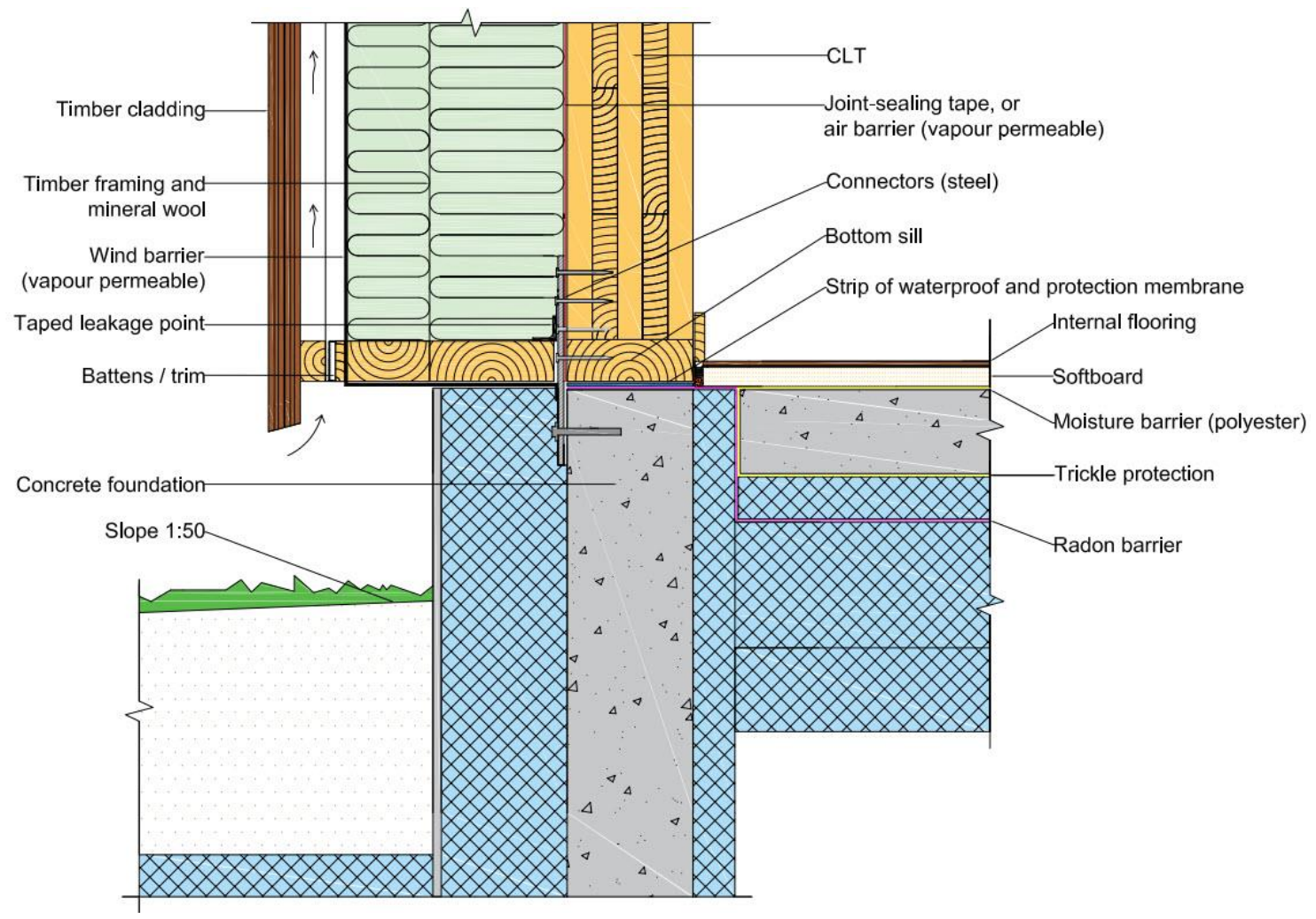

Fig. 2. Recommended design for the foundation of exterior CLT walls on a concrete floor slab [12]. 
Such information was useful in that it uncovered interesting aspects that had eluded initial consideration. One example of this was the use of wood fibre insulation systems, and this was added to the guide. Other comments highlighted linguistic errors and straightforward corrections, which commonly led to the reformulation of sentences and paragraphs in order to avoid misunderstanding.

\section{Discussion}

In this paper the author has set out to demonstrate how to prepare high-quality guidelines on the use of CrossLaminated Timber (CLT) elements in building construction. Quality assurance and reviews carried out by participating actors have indicated that the information collected and the guide itself may serve as a starting point for the preparation of updated CLT guidelines. However, there are some aspects of the method and its implementation that demand further discussion and illustration.

Analysis during the document study resulted in the classification of 30 construction details as highly relevant, extracted from the 408 documents available. This does not necessarily mean that the CLT method is unsuitable for use in residential buildings, but that actors are using CLT elements in more complex projects. If a higher priority had been assigned to searches of residential building projects, additional relevant details may have been revealed. Many construction details were not highlighted as relevant because CLT elements were used in combination with other materials. This indicates that it may be expedient to combine CLT with other materials, and that it is rare to use CLT exclusively in all building components. However, certain details, such as those related to the mounting of CLT elements, may be useful even if they are not highlighted. Another explanation for the occurrence of only few highlighted construction details is the fact that such details are created to serve a particular purpose for a specific project. A construction guide should ensure that its recommendations and illustrations are as generalised and flexible as possible. The task of converting the specific into the general is thus a challenging task. Illustrations taken from the handbooks produced in Sweden [12] and Austria [3] turned out to be just as relevant as the documents collected from the participating actors, confirming that the use of international literature constitutes an important source of information in the preparation of CLT guidelines. However, some adaptation to Norwegian building traditions was necessary, for instance in relation to the visibility requirement for CLT element surfaces in Norway.

Overall, the quality assurance process met its objective, as was demonstrated by the critical and supportive comments received. A detailed questionnaire may have provided the study with more uniform reviews, but such a process would have been too timeconsuming for widespread participation. The positive and supportive comments received indicate that the guide has presented key issues in the correct manner. If a topic had been dealt with incorrectly, this would have been pointed out by the actors [14]. The content of the guide was influenced by the reviews because information was added, thus supporting the aspects described in Section 2.3.

In this study, the methods applied have resulted in a large volume of information for analysis and interpretation, making extraction of the most essential information a challenging task. Evidence investigation using triangulation has been shown to be a useful tool in reviewing and highlighting the most critical topics. This process is reflected in the guide's limitations in terms of content. Building physics and moisture-safe design are controversial subjects that require clearer guidelines. The guide thus serves as a demonstration of the way in which CLT guidelines can be prepared. The topic of CLT construction is too complex for the current guide to be regarded as comprehensive.

The principle of triangulation is recurrent throughout this study, and the identification of corroborative findings enhances the validity and credibility of its results. Findings from the document study also support the findings of previous studies [6]. The quality assurance process has served to confirm the validity of the processed information presented in the construction guide and as such, the guide's content should be representative of the status of the CLT building construction method as applied in Norway today. It is hoped that the guide will inspire research institutions to develop updated literature on CLT building construction. SINTEF Community has already shown an interest in this study by means of its participation and guidance. This indicates that future research opportunities and the publishing of updated CLT literature is likely in the near future.

\section{Concluding remarks}

This study has demonstrated that it is possible to close a knowledge gap in the field of CLT construction using construction industry actors as a source of information, supported by guidance from the research community. Alternative sources of information have also been shown to be useful, especially when existing literature is limited. A combination of case study research methods has successfully stimulated involvement in the study by experienced professionals, resulting in a substantial volume of information for analysis and interpretation. The findings from interviews, the document study and the quality assurance process are mutually corroborative and highlight the most important topics in the field of CLT construction. An investigation of existing literature has been important in confirming findings from other sources. International literature has served as an important source in a situation where existing Norwegian literature is limited. The corroborative nature of the triangulation approach enhances the validity and credibility of the results.

The publication of a traditional SINTEF construction guide is a beneficial format for the presentation of the information processed during this study. This format is 
ideal for presenting instructions and illustrations in a way that makes it easier for the reader to comply with existing statutory building regulations. The need for updated guiding literature on CLT construction is reflected in the involvement in this study of both the industry and research institutions. Participating actors have expressed the importance of starting discussions and developing guidelines. Supportive and constructive comments resulting from the quality assurance process have influenced the content of the guide, which should now represent the state-of-the-art in CLT building construction in Norway.

In the future, research institutions will be devoting their efforts to the preparation and publication of updated and legally complaint CLT guidelines. It is hoped that the guide resulting from this study will inspire research institutions. The participation and involvement of, and the guidance provided by, SINTEF Community indicates that it is likely that further research into CLT construction and the publication of updated CLT literature is likely in the near future. However, these activities will require expertise and an adequate level of empirical experience in the field of CLT construction. Closer collaboration between the industry and the research institutions will be key to achieving higher levels of knowledge that will in turn facilitate the work to prepare future CLT construction guides.

The author wishes to thank professor Tore Kvande at the Department of Civil and Environmental Engineering at NTNU, also on the staff of the Klima 2050 research centre, for his close supervision of the M.Sc thesis of which this paper forms a part. The author also wished to thank all those who have given their time to participate in interviews and the document research and quality assurance processes.

\section{References}

1. M.F. Laguarda Mallo, O. Espinoza. Outlook for Cross-Laminated Timber in the United States. Bioresources.com 9(4) 7427-7443 (2014)

2. Regjeringen [Norwegian Government]. Markedet for massivtre er $i$ sterk vekst [CLT Market is Growing]. (2017) https://www.regjeringen.no/no/aktuelt/markedet-formassivtre-er-i-sterk-vekst/id2578870/

3. M. Teibinger, I. Matzinger. Construction with Cross-Laminated Timber in Multi-Storey Buildings. Wien: Holzforschung Austria (2013)

4. J.L. Skullestad, R.A. Bohne, J. Lohne. High-Rise Timber Buildings as a Climate Change Mitigation Measure - A Comparative LCA of Structural System Alternatives. Energy Procedia 96 p. 112 123 (2016)

5. L.G.F Tellnes. Fokus på tre $n r .58$. Miljødeklarasjoner for tre og trebaserte produkter [Focus on Wood 58 - Environmental Declarations for Wood-Based Products]. Oslo: Norsk Treteknisk Institutt (2016)

6. S. Wahlstrøm, L. Gullbrekken, K. Elvebakk, T. Kvande. Experiences with CLT Construction in Norway. To be submitted to 12th Nordic Symposium of Building Physics (NSB2020), Norwegian University of Science and Technology (2019)

7. B. Time, S. Geving, K.L. Friquin, S. Grynning, K. Noreng, K.M Sandland. Tak basert på massivtreelementer [CLT Based Roof Assemblies]. Project report 30. Trondheim: SINTEF Community; (2008)

8. H.B. Skogstad, L. Gullbrekken, S. Uvsløkk. Massivtre - Luftgjennomgang og behov for sperresjikt [CLT - Air Leaks and Barrier Layer Needs]. Project report 81. Trondheim: SINTEF Community (2011)

9. E. Aasheim. Håndbok - bygge med Massivtreelementer [Handbook - CLT Construction]. Oslo: Norsk Treteknisk Institutt (2006)

10. SINTEF Community. SINTEF Community. (2019) https://www.sintef.no/en/community/\#/

11. Norwegian Institute of Norwegian of Wood Technology. Publications. (2019) http://www.treteknisk.no/english/publications

12. E. Borgström, J. Fröbel. KL-trähandbok [CLT Handbook]. Stockholm: Svensktträ (2017).

13. S. Wahlstrøm. Anvisning for massivtrebygging [Guidelines for CLT Construction]. M.Sc thesis. Norwegian University of Science and Technology (2019)

14. R.K. Yin, Case Study Research. 5th ed. United States of America: Sage Publications p. 98-125 (2009)

15. Å.L. Hauge, C. Flyen, A.J. Almås, M. Ebeltoft. Klimatilpasning av bygninger og infrastruktur [Climate Adaptions in Buildings and Infrastructure]. Klima 2050 Report 04. Trondheim: SINTEF Community (2017)

16. G. Bowen. Document analysis as a qualitative research method. Qualitative research journal 9(2). p. 27-40 (2009)

17. R.P. Weber. Basic Content Analysis. 2nd edition. United States of America: Sage Publications (1990) 